\title{
Cost-effectiveness analysis of a single- inhaler triple therapy for COPD in the UK
}

\author{
Elisabeth Fenwick ${ }^{1}$, Alan Martin², Melanie Schroeder ${ }^{3}$, Stuart J. Mealing ${ }^{1}$, \\ Oyinkansola Solanke ${ }^{4}$, Nancy Risebrough ${ }^{5}$ and Afisi S. Ismaila ${ }^{6,7}$
}

Affiliations: "ICON Health Economics, ICON plc., Abingdon, UK. ${ }^{2}$ Value Evidence and Outcomes, GlaxoSmithKline plc., Uxbridge, UK. ${ }^{3}$ Value Evidence and Outcomes, GlaxoSmithKline plc., Brentford, UK. ${ }^{4}$ ICON Health Economics, ICON plc., London, UK. ${ }^{5}$ ICON Health Economics, ICON plc., Toronto, ON, Canada. ${ }^{6}$ Value Evidence and Outcomes, GlaxoSmithKline plc., Collegeville, PA, USA. ${ }^{7}$ Dept of Health Research Methods, Evidence and Impact, McMaster University, Hamilton, ON, Canada.

Correspondence: Afisi S. Ismaila, GlaxoSmithKline plc., 1250 South Collegeville Road, Collegeville, PA 194260989, USA. E-mail: afisi.s.ismailađagsk.com

ABSTRACT UK management costs for COPD, estimated at $£ 1.9$ billion/year, are rising. In the FULFIL (Lung Function and Quality of Life Assessment in Chronic Obstructive Pulmonary Disease with Closed Triple Therapy) study, single-inhaler triple therapy with fluticasone furoate/umeclidinium/vilanterol $(100 / 62.5 / 25 \mu \mathrm{g})$ improved clinical outcomes versus budesonide/formoterol $(400 / 12 \mu \mathrm{g})$ in patients with symptomatic COPD at risk of exacerbations. We assessed the cost-effectiveness of fluticasone furoate/ umeclidinium/vilanterol versus budesonide/formoterol for treating COPD from a UK National Health Service perspective.

A model was developed combining a trial-based and Markov component and populated with baseline and treatment effect data from FULFIL, together with UK healthcare resource costs and disease-related utilities. Costs per life year and per quality-adjusted life year gained (costing year 2017) for fluticasone furoate/umeclidinium/vilanterol versus budesonide/formoterol were calculated for a lifetime horizon. Results were explored using deterministic sensitivity, scenario and probabilistic analyses.

Fluticasone furoate/umeclidinium/vilanterol was associated with gains in life years (0.533) and qualityadjusted life years (0.506) versus budesonide/formoterol, but at slightly increased total costs ( $£ 26416$ versus $£ 25860$ ). This translated to incremental cost-effectiveness ratios of $£ 1042 /$ life year and $£ 1098$ /qualityadjusted life year for fluticasone furoate/umeclidinium/vilanterol versus budesonide/formoterol. In scenario analyses, incremental cost-effectiveness ratios ranged from dominant to $£ 1547 /$ quality-adjusted life year gained.

Fluticasone furoate/umeclidinium/vilanterol provides a cost-effective treatment option versus budesonide/formoterol for patients with symptomatic COPD in the UK.

@ERSpublications

This cost-effectiveness analysis demonstrates that fluticasone furoate/umeclidinium/vilanterol provides a cost-effective treatment option versus budesonide/formoterol for patients with symptomatic COPD in the UK https://bit.ly/3m6yfVo

Cite this article as: Fenwick E, Martin A, Schroeder M, et al. Cost-effectiveness analysis of a singleinhaler triple therapy for COPD in the UK. ERJ Open Res 2021; 7: 00480-2020 [https://doi.org/ 10.1183/23120541.00480-2020].

This article has supplementary material available from openres.ersjournals.com

Received: 8 July 2020 | Accepted after revision: 17 Nov 2020

Copyright $\odot$ ERS 2021. This article is open access and distributed under the terms of the Creative Commons Attribution Non-Commercial Licence 4.0. 


\section{Introduction}

The prevalence of COPD in the UK rose by $\sim 27 \%$ between 2004 and 2012 [1], and this increase is predicted to continue [2]. Maintenance pharmacological therapy for COPD centres on the use of long-acting bronchodilators in the form of a long-acting muscarinic antagonist (LAMA) and/or long-acting $\beta_{2}$-agonist (LABA). For patients who remain symptomatic despite inhaled corticosteroid (ICS)/ LABA or LAMA/LABA dual therapy and are at high risk of exacerbations, the Global Initiative for Chronic Obstructive Lung Disease (GOLD) recommends a triple combination of ICS plus a LAMA and LABA [3].

The Lung Function and Quality of Life Assessment in Chronic Obstructive Pulmonary Disease with Closed Triple Therapy (FULFIL) study was a phase III, randomised, double-blind, double-dummy trial (NCT02345161). FULFIL compared once-daily ICS/LAMA/LABA triple therapy using fluticasone furoate/ umeclidinium/vilanterol 100/62.5/25 $\mu \mathrm{g}$ (FF/UMEC/VI) administered via the ELLIPTA inhaler with twice-daily ICS/LABA therapy with budesonide/formoterol 400/12 $\mu \mathrm{g}$ (BUD/FOR) administered via the Turbuhaler inhaler. The study was conducted in patients with advanced, symptomatic COPD, who were at risk of exacerbations [4]. The findings from FULFIL demonstrated a statistically significant benefit in terms of trough forced expiratory volume in $1 \mathrm{~s}\left(\mathrm{FEV}_{1}\right)$ with FF/UMEC/VI within both the intent-to-treat (ITT) population, at 24 weeks, and a subpopulation of patients who remained on blinded treatment for an extended period of 52 weeks (extension (EXT) population) [4]. Thus, the clinical findings from FULFIL support the use of single-inhaler triple therapy over dual ICS/LABA therapy in patients with advanced, symptomatic COPD, who are at risk of exacerbations.

COPD represents a considerable cost to the UK economy; in 2017 this was estimated to be $\sim £ 1.9$ billion per year [5]. This, given the increasing prevalence of COPD, highlights the need to identify cost-effective therapeutic options with the potential to reduce exacerbations. Multiple models, capable of evaluating the cost-effectiveness of COPD treatments, have been developed [6]. These have predominantly been Markov models, representing COPD in terms of lung function and exacerbations. The exception is the GALAXY model, which uses an interdependent system of risk equations to characterise a wider set of disease attributes over time, including COPD symptoms and exercise capacity, in addition to lung function and exacerbations [7-9]. For this analysis, we chose to use a trial-based assessment combined with a Markov model focussing on lung function and exacerbation risk, like many previous models, rather than an approach similar to the GALAXY model. This allows the assessment of treatment value based on these two key outcomes for clinical decision-making in COPD, utilises a structure (Markov) which is familiar to Health Technology Assessment bodies and is less data intensive than the GALAXY model, which requires data inputs for a broader range of baseline characteristics and treatment effects.

Here we present a description of the approach and its application in the assessment of the cost-effectiveness of FF/UMEC/VI compared with BUD/FOR in the treatment of advanced, symptomatic COPD, from the perspective of the UK National Health Service (NHS).

\section{Methods}

\section{Model structure}

The model comprised an initial decision tree, representing the trial period, followed by a Markov model, with a 1-year cycle length, to extrapolate outcomes beyond the trial period. The initial trial-based analysis directly reflected the baseline status and outcomes ( 24 weeks for the ITT population, and 52 weeks for the EXT population) in FULFIL [4].

The Markov model consisted of six health states, plus death (figure 1). These were based on three categories of COPD severity defined by $\mathrm{FEV}_{1}$ status (moderate: $\mathrm{FEV}_{1} \%$ pred 50 to <80\%; severe: $\mathrm{FEV}_{1} \%$ pred 30 to $<50 \%$; and very severe: $\mathrm{FEV}_{1} \%$ pred $<30 \%$ ), each with two categories (presence or absence) of recent (previous year) exacerbation. Exacerbations could be either moderate (requiring treatment with antibiotics and/or systemic corticosteroids) or severe (requiring hospitalisation or resulting in death). Mild exacerbations were assumed to have a negligible impact on both clinical and economic outcomes, and therefore excluded. At the start of the Markov model, patients were assigned to one of the six health states in accordance with their $\mathrm{FEV}_{1}$ status at the end of, and exacerbation history during, the trial period.

Transitions between health states were determined by two risk equations, one predicting the rate of $\mathrm{FEV}_{1}$ decline over time, and the second the probability of an exacerbation (see below and supplementary appendix for details), together with the likelihood of dying. Costs, health-related quality of life and utility were assigned to health states and events (exacerbations and pneumonia events).

Estimated coefficients for variables in each equation are provided in supplementary table S1 and supplementary table S2. Baseline characteristics for age, percentage male and height were used to estimate decline in $\mathrm{FEV}_{1} \%$ pred, from which the probability of transition to a more severe state was calculated 


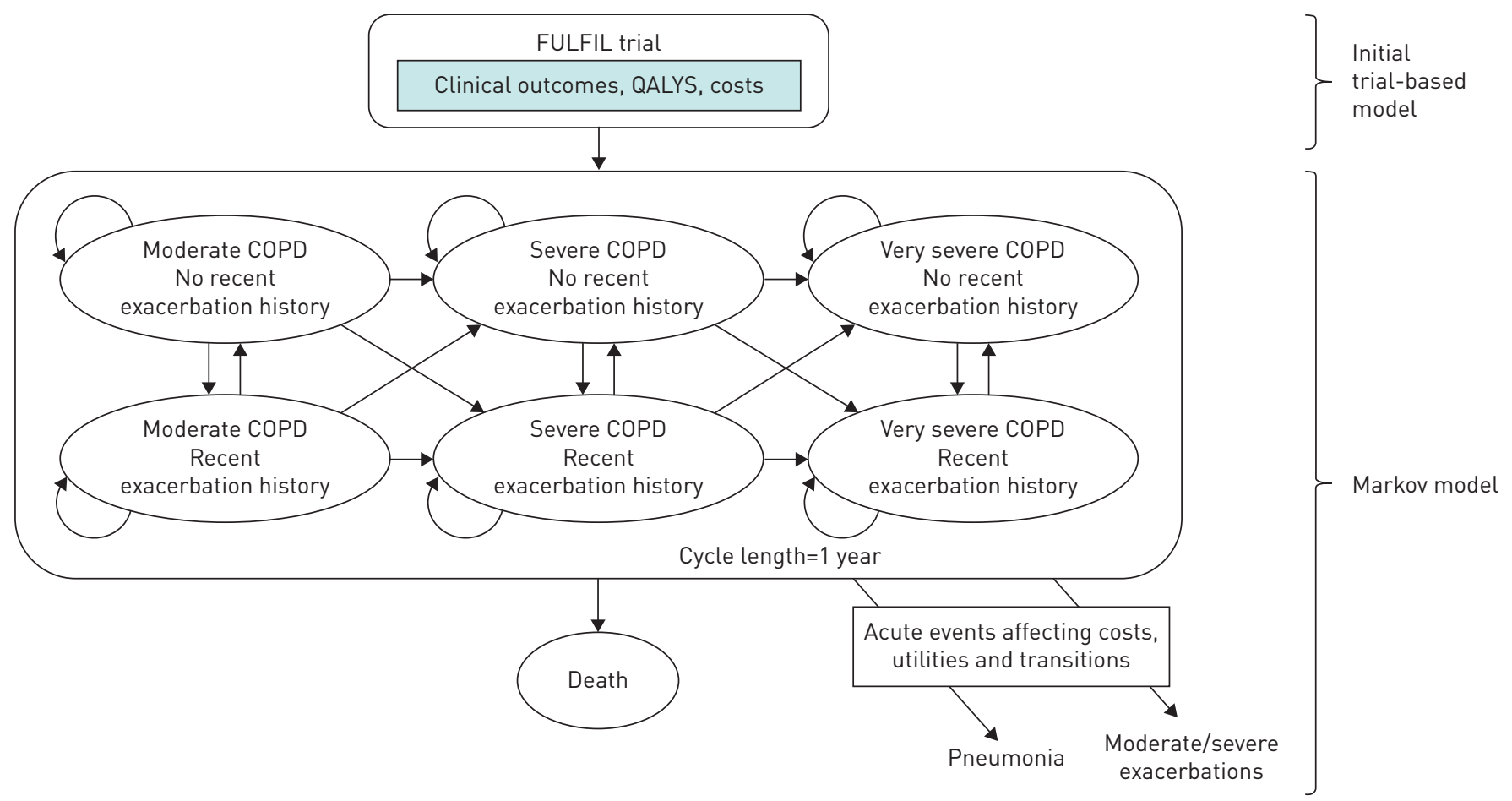

FIGURE 1 Conceptual COPD disease progression model. Moderate COPD (forced expiratory volume in $1 \mathrm{~s}(\mathrm{FEV}$ ) $\%$ pred 50 to $<80 \%$ ); severe COPD ( $F E V_{1} \%$ pred 30 to $<50 \%$ ); very severe COPD ( $F E V_{1} \%$ pred $<30 \%$ ). A recent exacerbation history is defined as an exacerbation occurring within the previous year. QALY: quality-adjusted life year.

(supplementary table S3). The assumption was made that individuals could only transition to increasingly severe COPD. The second equation predicted the probability of an exacerbation. Experiencing an exacerbation within a 1-year cycle impacted the transition rate to the next $\mathrm{FEV}_{1} \%$ pred state, as well as the risk of an exacerbation, during the immediately subsequent cycle. Both risk equations were developed using data from the 3-year Towards a Revolution in COPD Health (TORCH) study [10, 11].

\section{Model parameterisation}

\section{Patient characteristics}

Baseline patient characteristics used within the model are shown in table 1. Age and height data were drawn from the FULFIL study [4] and were used to calculate $\mathrm{FEV}_{1} \%$ pred. The remaining baseline characteristics [10] required to populate the risk equations for predicting annual $\mathrm{FEV}_{1}$ decline and exacerbation rate were derived from the TORCH study, since the data from this 3-year trial were used to develop the risk equations.

\section{Treatment effect}

Treatment effect was incorporated using results from FULFIL (supplementary table S4). This included, in addition to a reduction in within-trial exacerbations, a one-time shift in the distribution of the population across COPD severity health states, as a result of improvement in $\mathrm{FEV}_{1}$ at the end of the trial period. This formed the starting distribution for the Markov model (supplementary table S4). In the base case, this was assumed to fully capture the effect of treatment on disease progression and exacerbation risk, and the direct reduction in exacerbation rate from FULFIL was not applied in the Markov model. For assignment of costs and utilities in the initial trial period, the population was assumed to occupy the baseline health-state distribution for the first half of the trial period and the end-of-trial distribution for the second half.

Treatment-specific discontinuation rates from FULFIL were included for the trial period, with an assumption that there would be no further discontinuation in the Markov model (supplementary table S5). The assumption was made that only costs needed to be adjusted to account for discontinuation, as treatment effects for the ITT population would already include the impact of discontinuation. For calculation of costs, patients were assumed to receive replacement therapy (detailed in the next section). 


\begin{tabular}{|c|c|c|}
\hline Parameter & Value & Source \\
\hline Age at baseline years & $63.90 \pm 6.39$ & FULFIL [4] \\
\hline Height $\mathrm{m}$ & $1.69 \pm 0.08$ & FULFIL [4] \\
\hline \multicolumn{3}{|l|}{ Sex } \\
\hline Male & 75.8 & TORCH [10] \\
\hline \multicolumn{3}{|l|}{ Age category years } \\
\hline$<55$ & 11.5 & TORCH [10] \\
\hline 55 to $<65$ & 32.3 & TORCH [10] \\
\hline 65 to $<75$ & 43.7 & TORCH [10] \\
\hline$\geqslant 75$ & 12.6 & TORCH [10] \\
\hline \multicolumn{3}{|c|}{ Exacerbation history (moderate or severe, in the previous 12 months) } \\
\hline 0 & 43.0 & TORCH [10] \\
\hline 1 & 24.8 & TORCH [10] \\
\hline$\geqslant 2$ & 32.3 & TORCH [10] \\
\hline \multicolumn{3}{|l|}{ BMI $\mathrm{kg} \cdot \mathrm{m}^{-2}$} \\
\hline$<20$ & 13.5 & TORCH [10] \\
\hline 20 to $<25$ & 37.6 & TORCH [10] \\
\hline 25 to $<29$ & 26.9 & TORCH [10] \\
\hline$\geqslant 29$ & 22.0 & TORCH [10] \\
\hline \multicolumn{3}{|l|}{ SGRQ total score } \\
\hline$<38$ & 28.8 & TORCH [10] \\
\hline 38 to $<50$ & 25.7 & TORCH [10] \\
\hline 50 to $<62$ & 22.9 & TORCH [10] \\
\hline$\geqslant 62$ & 22.6 & TORCH [10] \\
\hline \multicolumn{3}{|l|}{ FEV $_{1} \%$ pred, baseline } \\
\hline$<30 \%$ & 12.9 & FULFIL [4] \\
\hline 30 to $<50 \%$ & 54.5 & FULFIL [4] \\
\hline 50 to $<80 \%$ & 32.6 & FULFIL [4] \\
\hline$\geqslant 80 \%$ & $<1.0$ & FULFIL [4] \\
\hline \multicolumn{3}{|c|}{$\begin{array}{l}\text { Data are presented as mean } \pm \text { SD or } \% \text {. \# : forced expiratory volume in } 1 \mathrm{~s}\left(\mathrm{FEV}_{1}\right) \% \text { pred at baseline was not } \\
\text { included in the model and is provided only as information describing lung function status at study entry. } \\
\text { BMI: body mass index; SGRQ: St. George's Respiratory Questionnaire; TORCH: Towards a Revolution in } \\
\text { COPD Health; FULFIL: Lung Function and Quality of Life Assessment in Chronic Obstructive Pulmonary } \\
\text { Disease with Closed Triple Therapy. }\end{array}$} \\
\hline
\end{tabular}

With the exception of pneumonia, FF/UMEC/VI and BUD/FOR showed comparable safety profiles in FULFIL [4]. Thus, pneumonia was the only adverse event included in the model, both in the trial period and Markov model, given the known association between ICS-containing treatment regimens and increased rates of pneumonia [12]. Rates for pneumonia were taken directly from FULFIL for the trial period; for the Markov model, annual probabilities based on data from TORCH were used [10, 13].

Resource use and unit costs

Drug acquisition costs for BUD/FOR were obtained from the British National Formulary (BNF 73, March 2017; www.bnf.org/); costs for FF/UMEC/VI were assumed to be the sum of the costs of FF/VI and UMEC as formal acquisition costs were not available at the time of the analysis. Based on the pack costs of $£ 49.50$ for 30 doses of FF/UMEC/VI and $£ 38.00$ for 60 doses of BUD/FOR, the weekly treatment costs in the trial-based model were calculated to be $£ 11.55$ and $£ 8.87$ for FF/UMEC/VI and BUD/FOR, respectively. In the trial period, patients who died or discontinued were assumed to have done so halfway through the trial period. Thus, those discontinuing treatment received treatment costs for 12 weeks and replacement therapy costs for the remaining 12 weeks. In the Markov model, patients who discontinued in the trial-based part of the model were assigned costs of replacement therapy, and all others were assigned treatment costs, while alive. Replacement therapy costs were based on the proportions of patients who received each of the four most frequently reported COPD medications following discontinuation in the FULFIL trial (ICS/LABA, ICS/LAMA/LABA, LAMA/LABA and LAMA) [4].

Exacerbation and pneumonia costs were calculated from resource use and unit cost data (table 2). Resource use was obtained from the literature [14]. Unit costs were derived from the UK 2015/16 NHS Reference Costs [15] and the Personal Social Services Research Unit (PSSRU) 2016 schedule [16] and were 


\section{TABLE 2 Itemised resource use and unit costs for COPD therapy and exacerbations}

\begin{tabular}{|c|c|c|c|}
\hline Cost category & $\begin{array}{l}\text { Resource use } \\
\text { (per annum/per } \\
\text { exacerbation) }\end{array}$ & $\begin{array}{l}\text { Unit cost } \\
(2017)^{\pi}\end{array}$ & $\begin{array}{c}\text { Overall cost } \\
\text { [per annum/per } \\
\text { exacerbation) }\end{array}$ \\
\hline \multicolumn{4}{|l|}{ Moderate COPD } \\
\hline Outpatient visit, respiratory physician & 0.00 & $€ 149.35$ & $€ 0.00$ \\
\hline Outpatient visit, GP & 2.00 & $€ 36.68$ & $€ 73.37$ \\
\hline Spirometry & 2.00 & $€ 61.57$ & $€ 123.15$ \\
\hline Influenza vaccination & 0.75 & $€ 9.05$ & $€ 6.79$ \\
\hline Oxygen therapy (days) & 0.00 & $€ 16.98$ & $€ 0.00$ \\
\hline Total cost of moderate COPD (per annum) & & & $£ 203.30$ \\
\hline \multicolumn{4}{|l|}{ Severe COPD } \\
\hline Outpatient visit, respiratory physician & 2.00 & $€ 149.35$ & $€ 298.71$ \\
\hline Outpatient visit, GP & 0.00 & $€ 36.68$ & $€ 0.00$ \\
\hline Spirometry & 2.00 & $€ 61.57$ & $€ 123.15$ \\
\hline Influenza vaccination & 0.75 & $€ 9.05$ & $€ 6.79$ \\
\hline Oxygen therapy (days) & 14.60 & €16.98 & $€ 247.86$ \\
\hline Total cost of severe COPD (per annum) & & & $€ 676.51$ \\
\hline \multicolumn{4}{|l|}{ Very severe COPD } \\
\hline Outpatient visit, respiratory physician & 4.00 & $€ 149.35$ & $€ 597.42$ \\
\hline Outpatient visit, GP & 0.00 & $€ 36.68$ & $€ 0.00$ \\
\hline Spirometry & 4.00 & $€ 61.57$ & $€ 246.29$ \\
\hline Influenza vaccination & 0.75 & $€ 9.05$ & $€ 6.79$ \\
\hline Oxygen therapy (days) & 73.00 & $€ 16.98$ & $€ 1239.32$ \\
\hline Total cost of very severe COPD (per annum) & & & $€ 2089.82$ \\
\hline \multicolumn{4}{|l|}{ Moderate exacerbation } \\
\hline ICU days & 0.00 & $€ 1341.52$ & $€ 0.00$ \\
\hline Non-ICU days & 1.01 & $€ 436.97$ & $€ 441.34$ \\
\hline ER visits & 0.03 & $€ 200.94$ & $€ 6.03$ \\
\hline Outpatient visit, respiratory physician & 0.34 & $€ 149.35$ & $€ 50.78$ \\
\hline Outpatient visit, GP & 0.66 & $€ 36.68$ & $€ 24.21$ \\
\hline Visit other HCP & 0.27 & $€ 98.52$ & $€ 26.60$ \\
\hline Antibiotics ${ }^{\pi}$ & 7.94 & $€ 0.28$ & $€ 2.21$ \\
\hline Systemic steroids" & 7.94 & $€ 0.27$ & $€ 2.11$ \\
\hline Oxygen therapy & 0.00 & $€ 16.98$ & $€ 0.00$ \\
\hline Total cost per moderate exacerbation & & & $€ 553.28$ \\
\hline \multicolumn{4}{|l|}{ Severe exacerbation } \\
\hline ICU days & 0.86 & $€ 1341.52$ & $€ 1153.71$ \\
\hline Non-ICU days & 11.08 & $€ 436.97$ & $€ 4841.63$ \\
\hline ER visits & 0.25 & $€ 200.94$ & $\mathrm{E} 50.24$ \\
\hline Outpatient visit, respiratory physician & 0.82 & $€ 149.35$ & $€ 122.47$ \\
\hline Outpatient visit, GP & 0.70 & $€ 36.68$ & $€ 25.68$ \\
\hline Visit other HCP & 0.50 & €98.52 & $€ 49.26$ \\
\hline Antibiotics & 11.75 & $€ 0.56$ & $€ 6.55$ \\
\hline Systemic steroids $\mathrm{s}^{\mathbb{}}$ & 24.08 & $€ 0.27$ & $€ 6.40$ \\
\hline Oxygen therapy & 0.21 & $€ 16.98$ & $€ 3.57$ \\
\hline Total cost per severe exacerbation & & & $€ 6259.49$ \\
\hline Cost per pneumonia event & & & $€ 6533.07$ \\
\hline
\end{tabular}

inflated to 2017. For the societal perspective, productivity costs associated with exacerbations were determined by multiplying the estimated length of exacerbation in days by the mean daily wage (£99.80) [17].

Mortality

The base case included mortality during the trial period based directly on data from FULFIL, in which there were four reported on-treatment deaths for FF/UMEC/VI, and six for BUD/FOR, up to Week 24 of the study [4]. Because event rates were low for deaths, with the consequent likelihood of treatment differences due to chance, excluding deaths in the trial period was explored in scenario analyses. In the 
Markov phase, excess mortality due to COPD was modelled using severity-specific relative risks of death applied to background all-cause mortality from England and Wales life tables [18]. Relative risks were calculated from a study of mortality rates in moderate, severe and very severe COPD and non-COPD populations [19].

\section{Health-related quality of life}

Health-state utilities (table 3) were obtained from a previously published analysis [20] using data from the multinational Understanding Potential Long-term Impacts on Function with Tiotropium (UPLIFT) trial [21]. Utilities in the UPLIFT trial were elicited using the EQ-5D instrument from a subset of trial patients with characteristics similar to those of the overall trial population [20]. Decrements in quality-adjusted life years (QALYs) were applied to exacerbation and pneumonia events and calculated using an area-under-the-curve approach with each event assumed to last 12 weeks [22].

\section{Analyses}

Model outputs included numbers of exacerbations, costs (total and disaggregated), life years (LYs), QALYs and incremental cost-effectiveness ratios (ICERs) as incremental cost per LY or QALY gained. In order to capture all relevant costs and outcomes of treatments, a lifetime horizon was adopted for the base case. To align with the National Institute for Health and Care Excellence (NICE) reference case [23], a discount rate of $3.5 \%$ per annum was applied to both costs and benefits in the base case.

Scenario analyses explored the impact of alternative assumptions or model settings on the model results. The impact of uncertainty around input parameters and risk equation coefficients was explored in deterministic one-way sensitivity analyses (OWSA) and probabilistic analysis. Supplementary table S6 provides upper and lower limits for input values of parameters included in the OWSA. The probabilistic analysis (10000 Monte Carlo simulations) was conducted with random sampling from distributions assigned to input parameters (supplementary table S7). Risk equation coefficients were included in the probabilistic analysis via Cholesky decomposition [24].

Subgroup analyses were conducted for the EXT population and two other subgroups: patients whose COPD was severe or worse (defined as $\mathrm{FEV}_{1} \%$ pred $<50 \%$ ), and patients with an exacerbation history of $\geqslant 1$ severe or $\geqslant 2$ moderate exacerbations in the 12 months prior to randomisation.

\section{Results}

Base-case analysis

In the ITT population, FF/UMEC/VI was associated with fewer cumulative exacerbations per patient compared with BUD/FOR over a lifetime horizon (table 4). Total costs were slightly higher for FF/UMEC/VI than for BUD/FOR (incremental difference $£ 556$ ). Accumulated LYs and QALYs were also slightly greater with FF/UMEC/VI compared with BUD/FOR (incremental LYs 0.533 and incremental QALYs 0.506). This led to an ICER of $£ 1042$ per LY gained and $£ 1098$ per QALY gained for FF/UMEC/VI compared with $\mathrm{BUD} / \mathrm{FOR}$

\section{Scenario and sensitivity analyses}

In scenario analyses, ICERs for FF/UMEC/VI compared with BUD/FOR ranged from dominant (lower costs and better outcomes) to $£ 1547$ per QALY gained (table 5). Applying a direct post-trial treatment

\section{TABLE 3 Health-state utilities and QALY loss associated with each event}

\begin{tabular}{|c|c|c|c|}
\hline Health state ${ }^{\#}$ & Utility & Lower $95 \% \mathrm{Cl}$ & Upper $95 \% \mathrm{Cl}$ \\
\hline Moderate COPD & 0.787 & 0.771 & 0.802 \\
\hline Severe COPD & 0.750 & 0.731 & 0.768 \\
\hline Very severe COPD & 0.647 & 0.598 & 0.695 \\
\hline Event & QALY loss per event & Lower $95 \% \mathrm{Cl}$ & Upper $95 \% \mathrm{Cl}$ \\
\hline Moderate exacerbation" & 0.011 & 0.006 & 0.020 \\
\hline Severe exacerbation" & 0.020 & 0.020 & 0.030 \\
\hline Pneumonia $^{+}$ & 0.011 & 0.006 & 0.020 \\
\hline
\end{tabular}

QALY: quality-adjusted life year; NICE: National Institute for Health and Care Excellence. ${ }^{\#}$ : source RUTTENvAN MöLKEN et al. [20]; ๆ: source NICE Guidelines, 2010 [22]; ${ }^{+}$: assumption: equivalent to moderate exacerbation. 


\begin{tabular}{|c|c|c|c|}
\hline & FF/UMEC/VI & BUD/FOR & Incremental \\
\hline \multicolumn{4}{|l|}{ Outcomes } \\
\hline \multicolumn{4}{|l|}{ Predicted cumulative exacerbations } \\
\hline Moderate exacerbations & 5.793 & 5.804 & -0.011 \\
\hline Severe exacerbations & 1.422 & 1.434 & -0.012 \\
\hline Any moderate and/or severe exacerbation & 7.216 & 7.238 & -0.023 \\
\hline Total LYs (discounted) & 9.094 & 8.561 & 0.533 \\
\hline Total QALYs (discounted) & 6.638 & 6.132 & 0.506 \\
\hline \multicolumn{4}{|l|}{ Costs } \\
\hline Maintenance & $€ 7531$ & $€ 8495$ & $-€ 965$ \\
\hline Moderate exacerbation & $€ 2459$ & $€ 2484$ & $-€ 25$ \\
\hline Severe exacerbation & $€ 6874$ & $€ 6974$ & $-€ 100$ \\
\hline Pneumonia & $€ 4261$ & $€ 3927$ & $€ 334$ \\
\hline Treatment & $€ 4887$ & $€ 3339$ & $€ 1549$ \\
\hline Discontinuation & $€ 404$ & €641 & $-€ 237$ \\
\hline Total costs & $€ 26416$ & $€ 25860$ & $€ 556$ \\
\hline ICER per LY & $€ 1042$ & Referent & \\
\hline ICER per QALY & $€ 1098$ & Referent & \\
\hline
\end{tabular}

effect on exacerbations in the Markov model had the greatest impact on the ICER: assuming the duration of this effect to be 1 year resulted in an ICER of $£ 255$ per QALY gained; longer durations, with or without waning of treatment effect over time, resulted in FF/UMEC/VI dominating BUD/FOR. Restricting the time horizon of the model to equal that of the trial follow-up period also resulted in FF/UMEC/VI being dominant.

OWSA demonstrated that cost-effectiveness was most sensitive to drug acquisition costs (figure 2). Varying the costs of FF/UMEC/VI or BUD/FOR by $\pm 20 \%$ resulted in ICERs ranging from dominant (-£829) to $£ 3026$ per QALY gained. Varying the utility of moderate COPD and the risk associated with mortality in very severe COPD by $\pm 20 \%$ also had some impact on cost-effectiveness, with ICERs (cost per QALY gained) ranging from $£ 796$ to $£ 1773$, and $£ 577$ to $£ 1447$, respectively. The ICER remained below the accepted NICE cost-effectiveness threshold of $£ 20000$ per QALY gained [23] in all of the deterministic sensitivity or scenario analyses.

TABLE 5 Scenario analyses (FF/UMEC/VI versus BUD/FOR), intent to treat population

\begin{tabular}{lccc} 
& Base case & Scenario & $\begin{array}{c}\text { FF/UMEC/VI ICER } \\
\text { (cost per QALY gained) }\end{array}$ \\
\hline Base case & & & $£ 1098$ \\
Discount rate (costs, benefits) & $3.5 \%$ & $0.0 \%$ & $£ 1547$ \\
Discount rate (costs, benefits) & $3.5 \%$ & $5.0 \%$ & $€ 900$ \\
Within-trial mortality & On & Off & $£ 1011$ \\
Post-trial treatment effect & Off & On - 1 year & $€ 255$ \\
Post-trial treatment effect & Off & On - 3 years & Dominant \\
Post-trial treatment effect & Off & On - 5 years & Dominant \\
Post-trial treatment effect - waning & Off & On - 5 years & Dominant \\
Overall treatment discontinuation & On & Off & $£ 1414$ \\
Post-trial treatment discontinuation & On & Off & $£ 1414$ \\
Time horizon & Lifetime & Trial follow-up & Dominant \\
Replacement therapy & By treatment arm & By overall trial & $£ 1098$ \\
Perspective & Health service & Societal & $£ 886$ \\
& perspective & perspective &
\end{tabular}

FF: fluticasone furoate; UMEC: umeclidinium; VI: vilanterol; BUD: budesonide; FOR: formoterol; ICER: incremental cost-effectiveness ratio; QALY: quality-adjusted life year. 


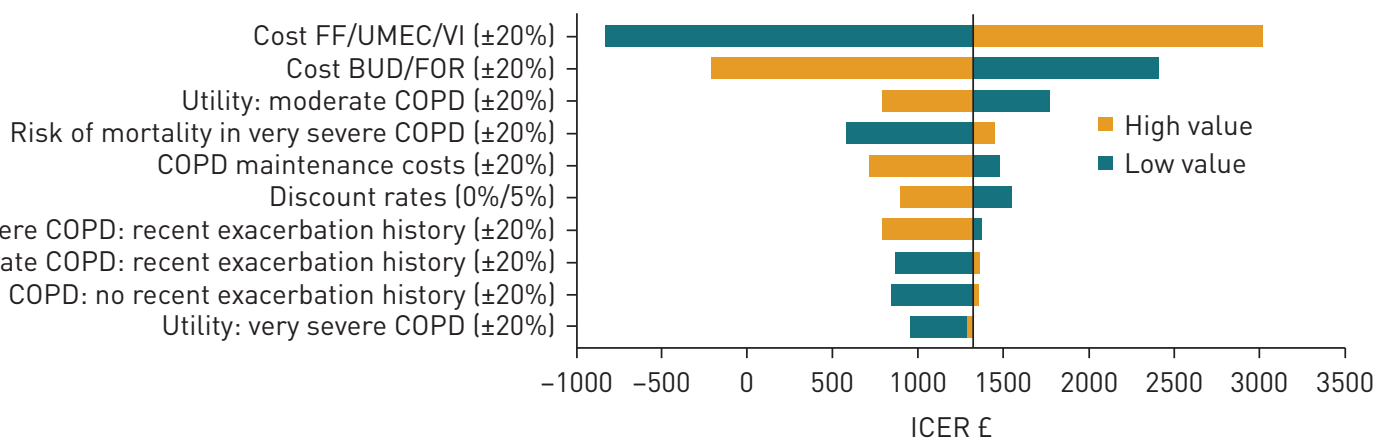

FIGURE 2 One-way sensitivity analysis plot (quality-adjusted life years (QALYs); intent to treat (ITT) population). FF: fluticasone furoate; UMEC: umeclidinium; VI: vilanterol; BUD: budesonide; FOR: formoterol; ICER: incremental cost-effectiveness ratio.

\section{Subgroup analyses}

Results in the EXT population were similar to the base case, with FF/UMEC/VI associated with fewer cumulative exacerbations per patient compared with BUD/FOR over a lifetime horizon (supplementary table S8). Total costs of FF/UMEC/VI were lower than for BUD/FOR (incremental difference -£101). Accumulated LYs and QALYs were greater with FF/UMEC/VI compared with BUD/FOR with incremental gains of 0.666 and 0.643 , respectively. In terms of cost-effectiveness, the ICERs per LY and QALY gained for FF/UMEC/VI compared with BUD/FOR were both dominant. Results in the two other subgroup populations - severe COPD or worse, and a history of exacerbations - were also similar to the base case, with ICERs of $£ 1172$ and $£ 864$ per QALY gained, respectively (supplementary table S8).

\section{Probabilistic analysis}

In the probabilistic analysis, FF/UMEC/VI was associated with improved outcomes in all iterations, both for LYs (figure 3a; supplementary figure S1a) and QALYs (figure 3b; supplementary figure S1b). Furthermore, FF/UMEC/VI was associated with a $100 \%$ probability of cost-effectiveness at willingness-to-pay thresholds of $£ 10000$ and $£ 20000$ [23] in both the ITT (figure 3c) and EXT (supplementary figure S1c) patient populations.

\section{Discussion}

This analysis assessed the cost-effectiveness of treating patients with advanced, symptomatic COPD with FF/UMEC/VI or BUD/FOR from the UK NHS perspective, using data from the FULFIL study. Total costs were slightly higher with FF/UMEC/VI, but there were fewer COPD exacerbations and increased LYs and QALYs compared with BUD/FOR, with the result that FF/UMEC/VI was predicted to be highly cost-effective versus BUD/FOR. FF/UMEC/VI remained cost-effective across a series of sensitivity and scenario analyses, and in probabilistic analysis the probability of FF/UMEC/VI being cost-effective at the NICE willingness-to-pay threshold of $£ 20000$ /QALY gained [23] was $100 \%$. Across all analyses, FF/ UMEC/VI was associated with improved outcomes (in LYs and QALYs). Higher costs were due to increased costs associated with longer overall survival associated with FF/UMEC/VI while increased effectiveness was as a result of lower exacerbation incidence during the trial period across all patient populations. These findings are important for decisions on the treatment of COPD in the UK NHS.
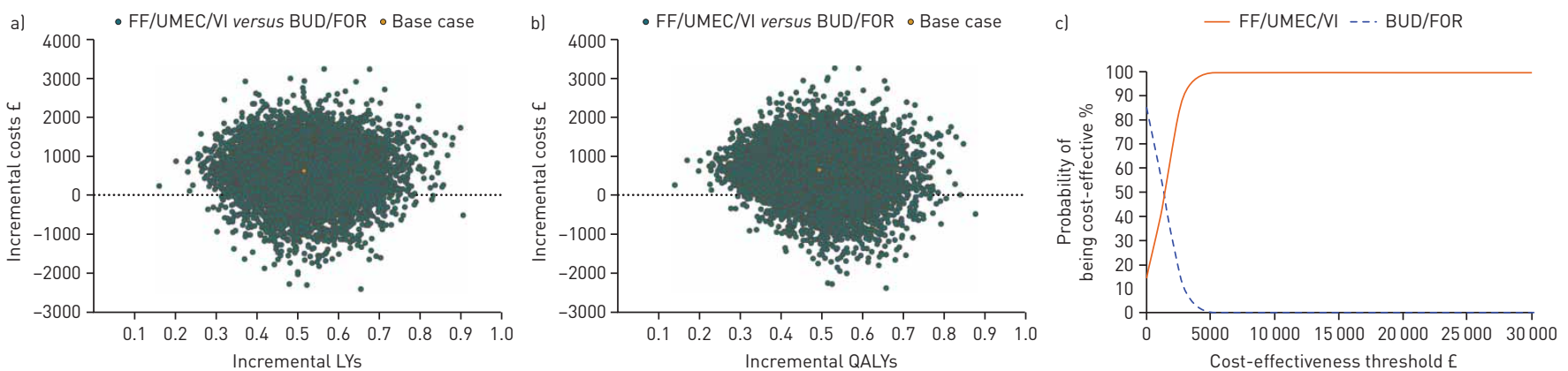

FIGURE 3 Incremental cost-effectiveness of fluticasone furoate (FF)/umeclidinium (UMEC)/vilanterol (VI) versus budesonide (BUD)/formoterol (FOR): (a) life year (LY) plane; (b) quality-adjusted life year (QALY) plane; (c) QALY cost-effectiveness acceptability curves (intent to treat (ITT) population; probabilistic analysis). 
It is helpful to understand how relevant the results of this analysis, which was based on data from a controlled trial, are for patients treated in real practice. FULFIL was designed to be highly inclusive and enrolled patients with COPD irrespective of whether they also had cardiovascular risk factors [4]; this contrasts with many other COPD clinical trials which often exclude such patients [25]. Patients did not have to artificially withdraw from their usual medications to participate, thus the study population had similar characteristics to patients with COPD in the real-world setting. Furthermore, the mean age (63.9 years) and current smoking status (44\%) of the ITT population in FULFIL [4] were similar to those reported in a large database study of 9219 patients with COPD in UK primary care [26]. This, together with the consistency of results across subgroups and the ITT population, strongly suggests that the findings of this analysis are generalisable to the population of patients with COPD in the UK.

The findings of this analysis are similar to those reported recently by Schroeder et al. (2019) [27] in their analysis of the cost-effectiveness of FF/UMEC/VI versus BUD/FOR, also based on data from the FULFIL trial. Using the GALAXY linked-risk equation model, FF/UMEC/VI resulted in gains in LYs (0.764) and QALYs (0.492), at an additional cost (£1652), compared with BUD/FOR; this translated to an ICER per QALY gained of $£ 3357$ [27]. A similar QALY gain (0.506) was observed in this analysis, but with a lower ICER per QALY gained (£1098). The current analysis used a Markov modelling approach that requires fewer input data, suggesting that the results derived may be more accessible to regulatory bodies. When considered alongside the findings reported by SCHROEDER et al. [27], this analysis demonstrates the cost-effectiveness of FF/UMEC/VI relative to BUD/FOR in the UK NHS setting.

A potential limitation of this analysis is the absence of data on longer-term treatment effects in FULFIL. Risk equations, based on data from the 3-year TORCH trial, were used to bridge to longer-term outcomes. Although the populations in FULFIL and TORCH were quite similar with respect to age, lung function and smoking status, there may be limitations to how generalisable outcomes in TORCH are to the FULFIL or other populations. This is important to note, as sensitivity analyses within the model showed that results were sensitive to the duration and nature of long-term treatment effects on exacerbation frequency. However, longer-term differences between FF/UMEC/VI and BUD/FOR, predicted by the risk equations, were substantially smaller than those observed in FULFIL, suggesting that the base case is conservative. Furthermore, given all sensitivity and scenario analyses were well below the accepted willingness-to-pay threshold in the UK, uncertainty over long-term effects does not appear to cast doubt on the findings of this analysis. Additionally, as treatment adherence in a clinical trial setting is typically greater than that observed in the real-world setting, it is possible that the full benefit of FF/UMEC/VI once-daily versus BUD/FOR twice-daily treatment was not fully realised in the original FULFIL trial. If this were the case, the results of this analysis would be conservative with respect to the cost-effectiveness of FF/UMEC/VI in routine practice.

\section{Conclusions}

Treatment with FF/UMEC/VI is predicted to improve long-term health outcomes and provide a cost-effective option for treatment of patients with advanced, symptomatic COPD when compared with $\mathrm{BUD} / \mathrm{FOR}$, in the UK.

Data availability: Anonymised individual participant data and study documents can be requested for further research from www.clinicalstudydatarequest.com

Acknowledgements: The authors would like to acknowledge Damir Vetrini, formerly of ICON Health Economics, ICON plc., Abingdon, UK, and currently HEMAR Manager, The Janssen Pharmaceutical Companies of Johnson \& Johnson, for his contributions to the study design and data analysis. The authors also thank Karissa Johnston, Principal and Scientific Director at Broadstreet Health Economics \& Outcomes Research, Vancouver, Canada for her contribution to the risk equation analysis. Medical writing support in the form of development of the draft outline and manuscript first draft in consultation with the authors, editorial suggestions to draft versions of this paper, assembling tables and figures, collating author comments, copyediting, referencing and graphic services was provided by Sarah Birch, Contract Senior Medical Writer of Gardiner-Caldwell Communications, Macclesfield, UK and was funded by GlaxoSmithKline plc. Trademarks are owned by or licensed to their respective owners (the GlaxoSmithKline group of companies or AstraZeneca).

Author contributions: A. Martin, M. Schroeder: study design and data interpretation. O. Solanke, A.S. Ismaila, S.J. Mealing: study design, data analysis and interpretation. O. Solanke: data acquisition. E. Fenwick, N. Risebrough: data analysis and data interpretation. All authors were involved in the writing, reviewing and final approval of the manuscript.

Conflict of interest: E. Fenwick reports GSK provided funds to ICON plc to build the model and conduct the analysis in the present study. A. Martin is an employee of GlaxoSmithKline. M. Schroeder was an employee and shareholder of GlaxoSmithKline plc at the time of the study. S.J. Mealing reports grants from GlaxoSmithKline plc during the conduct of the study and outside the submitted work, all of which were paid to ICON Health Economics. O. Solanke reports personal fees from GlaxoSmithKline plc during the conduct of the study. N. Risebrough has nothing to disclose. 
A.S. Ismaila reports the study was funded GlaxoSmithKline, of which A.S. Ismaila is an employee and shareholder. A.S. Ismaila is also an unpaid, part-time professor at McMaster University.

Support statement: The FULFIL study (NCT02345161; GSK study CTT116853) was funded by GlaxoSmithKline plc. This cost-effectiveness analysis was also funded by GlaxoSmithKline plc. (study HO-16-13835). Funding information for this article has been deposited with the Crossref Funder Registry.

\section{References}

1 Snell N, Strachan D, Hubbard R, et al. Epidemiology of chronic obstructive pulmonary disease (COPD) in the UK: findings from the British Lung Foundation's 'Respiratory Health of the Nation' project. Thorax 2016; 71: A20.

2 McLean S, Hoogendoorn M, Hoogenveen RT, et al. Projecting the COPD population and costs in England and Scotland: 2011 to 2030. Sci Rep 2016; 6: 31893.

3 Global Initiative for Chronic Obstructive Lung Disease (GOLD). Global strategy for the diagnosis, management, and prevention of chronic obstructive pulmonary disease. 2020 report. https://goldcopd.org/wp-content/uploads/ 2019/11/GOLD-2020-REPORT-ver1.0wms.pdf Date last accessed: February 2021; date last updated: 2020.

4 Lipson DA, Barnacle H, Birk R, et al. FULFIL trial: once-daily triple therapy for patients with chronic obstructive pulmonary disease. Am J Respir Crit Care Med 2017; 196: 438-446.

5 British Lung Foundation. The battle for breath - the economic burden of lung disease. www.blf.org.uk/what-wedo/our-research/economic-burden Date last accessed: February 2021; date last updated: 2017.

6 Hoogendoorn M, Feenstra TL, Asukai Y, et al. External validation of health economic decision models for chronic obstructive pulmonary disease (COPD): report of the third COPD modeling meeting. Value Health 2017; 20: 397-403.

7 Risebrough NA, Briggs A, Baker TM, et al. Validating a model to predict disease progression outcomes in patients with COPD. Value Health 2014; 17: A560-A561.

8 Briggs $\mathrm{AH}$, Baker T, Risebrough NA, et al. Development of the Galaxy chronic obstructive pulmonary disease (COPD) model using data from ECLIPSE: internal validation of a linked-equations cohort model. Med Decis Making 2017; 37: 469-480.

9 Exuzides A, Colby C, Briggs AH, et al. Statistical modeling of disease progression for chronic obstructive pulmonary disease using data from the ECLIPSE study. Med Decis Making 2017; 37: 453-468.

10 Calverley PM, Anderson JA, Celli B, et al. Salmeterol and fluticasone propionate and survival in chronic obstructive pulmonary disease. N Engl J Med 2007; 356: 775-789.

11 Vestbo J, TORCH Study Group. The TORCH (towards a revolution in COPD health) survival study protocol. Eur Respir J 2004; 24: 206-210.

12 Morjaria JB, Rigby A, Morice AH. Inhaled corticosteroid use and the risk of pneumonia and COPD exacerbations in the UPLIFT study. Lung 2017; 195: 281-288.

13 Crim C, Calverley PM, Anderson JA, et al. Pneumonia risk in COPD patients receiving inhaled corticosteroids alone or in combination: TORCH study results. Eur Respir J 2009; 34: 641-647.

14 Oostenbrink JB, Rutten-van Mölken MP, Monz BU, et al. Probabilistic Markov model to assess the cost-effectiveness of bronchodilator therapy in COPD patients in different countries. Value Health 2005; 8: 32-46.

15 National Health Service (NHS). NHS reference costs collection guidance for 2015 to 2016. www.gov.uk/ government/publications/nhs-reference-costs-collection-guidance-for-2015-to-2016 Date last accessed: February 2021; date last updated: 2016.

16 Personal Social Services Research Unit. Unit costs of health and social care 2016. www.pssru.ac.uk/project-pages/ unit-costs/2016/ Date last accessed: February 2021; date last updated: 2016.

17 Office for National Statistics. Earnings and Working Hours. www.ons.gov.uk/employmentandlabourmarket/ peopleinwork/earningsandworkinghours Date last accessed: February 2021; date last updated: December 2016.

18 Office for National Statistics. Deaths registered in England and Wales: 2015. www.ons.gov.uk/ peoplepopulationandcommunity/birthsdeathsandmarriages/deaths/bulletins/deathsregistrationsummarytables/2015 Date last accessed: February 2021; date last updated: 2015.

19 Afonso AS, Verhamme KM, Sturkenboom MC, et al. COPD in the general population: prevalence, incidence and survival. Respir Med 2011; 105: 1872-1884.

20 Rutten-van Mölken MP, Oostenbrink JB, Tashkin DP, et al. Does quality of life of COPD patients as measured by the generic EuroQol five-dimension questionnaire differentiate between COPD severity stages? Chest 2006; 130: $1117-1128$

21 Tashkin DP, Celli B, Senn S, et al. A 4-year trial of tiotropium in chronic obstructive pulmonary disease. $N$ Engl J Med 2008; 359: 1543-1554.

22 National Institute for Health and Care Excellence. Chronic obstructive pulmonary disease: management of chronic obstructive pulmonary disease in adults in primary and secondary care (2009). www.nice.org.uk/guidance/cg101/ documents/chronic-obstructive-pulmonary-disease-update-nice-draft-guideline2 Date last accessed: February 2021; date last updated: 2010

23 National Institute for Health and Care Excellence. The guidelines manual. Process and methods [PMG6]. 7. Assessing cost effectiveness (2012). www.nice.org.uk/process/pmg6/chapter/assessing-cost-effectiveness Date last accessed: February 2021; date last updated: 2012.

24 Weisstein EW. Cholesky decomposition. www.mathworld.wolfram.com/CholeskyDecomposition.html Date last accessed: February 2021; date last updated: February 2021

25 Rabe KF, Hurst JR, Suissa S. Cardiovascular disease and COPD: dangerous liaisons? Eur Respir Rev 2018; 27 180057.

26 Haughney J, Gruffydd-Jones K, Roberts J, et al. The distribution of COPD in UK general practice using the new GOLD classification. Eur Respir J 2014; 43: 993-1002.

27 Schroeder S, Shah D, Risebrough N, et al. Cost-effectiveness analysis of a single-inhaler triple therapy for patients with advanced chronic obstructive pulmonary disease (COPD) using the FULFIL trial: a UK perspective. Respir Med X 2019; 1: 100008 